\title{
Effect of Multiwall Carbon Nanotubes (MWCNs) Reinforcement on the Mechanical Behavior of Synthesis 7075 Aluminum Alloy Composites by Mechanical Milling
}

\author{
C. Carreño-Gallardo ${ }^{1}$, E. Uriza-Vega ${ }^{1}$, I. Estrada-Guel ${ }^{1}$, M. Herrera-Ramírez $^{1}$, R. Martínez-Sánchez ${ }^{1}$, C. \\ López-Meléndez ${ }^{2}$ and E. Martínez-Franco ${ }^{3}$ \\ 1. Centro de Investigación en Materiales Avanzados (CIMAV). Laboratorio Nacional de \\ Nanotecnología. Miguel de Cervantes No. 120, Chihuahua, Chih., México. \\ 2. Universidad La Salle Chihuahua, Prol. Lomas de Majalca No. 11201, Chihuahua, México. \\ 3. Centro de Ingeniería y Desarrollo Industrial (CIDESI). Av. Playa Pie de la Cuesta No. 702, Querétaro \\ México.
}

Aluminum alloys are preferred engineering material for automobile, aerospace and mineral processing industries for various high performing components that are being used for varieties of applications owing to their lower weight, excellent thermal conductivity properties. Aluminum alloy7075 possesses very high strength, higher toughness and are preferred in aerospace and automobile sector [1-3]. The composites formed out of aluminum alloys are of wide interest owing to their high strength, fracture toughness, wear resistance and stiffness.

The purpose of the present work is to produce the carbon multiwall carbon nanotubes (MWCNs) reinforced MMCs by mechanical milling (MM), examine the mechanical behavior after the incorporation of MWCNs in 7075 aluminum alloy in function of nanotubes percentage of concentration, distribution and size on the microstructure and identify strengthening mechanism presents.

Raw materials were 7075 aluminum alloy as the metal matrix and MWCNTs with a mean diameter of $100 \mathrm{~nm}$ as reinforcement agent. Initial aluminum alloy burrs were produced by machining of commercial solid bar. These coarse powders were mixed with MWCNTs at different concentrations; chemical composition of Al7075 is shown in Table 1. The mechanical milling of powder mixture was performed in a high-energy SPEX 8000 mill, under an inert atmosphere of pure argon gas. The milling container was made of stainless steel and milling media was made of hardened chrome steel, 5 drops of methanol was used as a process control agent (PCA) to avoid excessive cold-welding of the powder particles. The A17075-MWCNT composite powders used to prepare compression samples were ball milled for 2 hours. A blank (Al 7075) sample without any reinforcement addition was produced under the same conditions for comparison purposes. The milling ball-to-powder weight ratio was set at 5:1.

Figure 1 shows TEM high magnification image of an individual well graphitized MWCNT, revealing the morphology and length

Figure 2 shows FE SEM image of the fracture surface of 1wt\% MWNTC/A17075 and showing dispersed MWCNTs (indicated by arrows) within the Al 7075 matrix.

Figure 3 shows the yield strength behavior of compression test (a) curves of the A17075 specimen show $225 \mathrm{MPa}$ and the yield stress of $1 \mathrm{wt} \% \mathrm{MWNTC} / \mathrm{Al} 7075$ (b) is dramatically enhanced show $392 \mathrm{MPa}$. The yield strength of the CNT/Al composite with $1 \mathrm{~h}$ ball-milling increased by $57.4 \%$ compared with the Al 7075 matrix with the same processing history. 
NOTE: The compression test is reported only for pure A17075 and 1wt\% MWNTC/A17075, the results for other concentrations will be explained in the congress [4].

\section{References:}

[1] ASM Handbook of Composites (2001).

[2] Dai H. Surf Sci 500 (2002), p. 218.

[3] Wang Y et al, Nature 419 (2002), p. 91.

[4] The authors acknowledge to the Red Temática Nacional de Aeronáutica, Red Materiales Compuestos and Red Temática de Nanociencias y Nanotecnología (152992).

Table 1. Chemical composition Al7075 by weight percentage.

\begin{tabular}{cccccccccc}
\hline $\begin{array}{c}\text { Chemical } \\
\text { composition }\end{array}$ & Al & $\mathbf{C r}$ & $\mathbf{C u}$ & $\mathbf{F e}$ & $\mathbf{M g}$ & $\mathbf{M n}$ & $\mathbf{S i}$ & $\mathbf{T i}$ & $\mathbf{Z n}$ \\
$\begin{array}{c}\text { Al 7075 } \\
\text { Bal }\end{array}$ & $0.18-0.28$ & $1.20-2.00$ & $0.00-0.50$ & $2.10-2.90$ & $0.00-0.30$ & $0.00-0.40$ & $0.00-0.20$ & $5.10-6.10$ \\
\hline
\end{tabular}

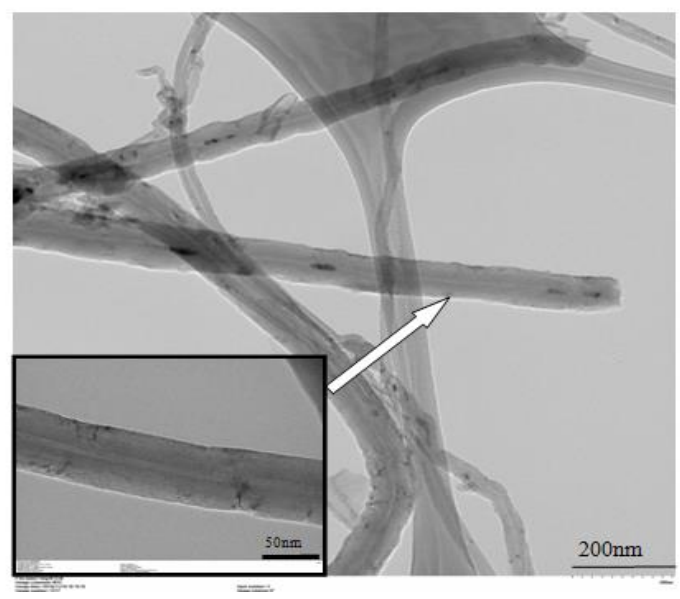

Figure 1. Transmission electron micrographs of as-received MWCNTs.

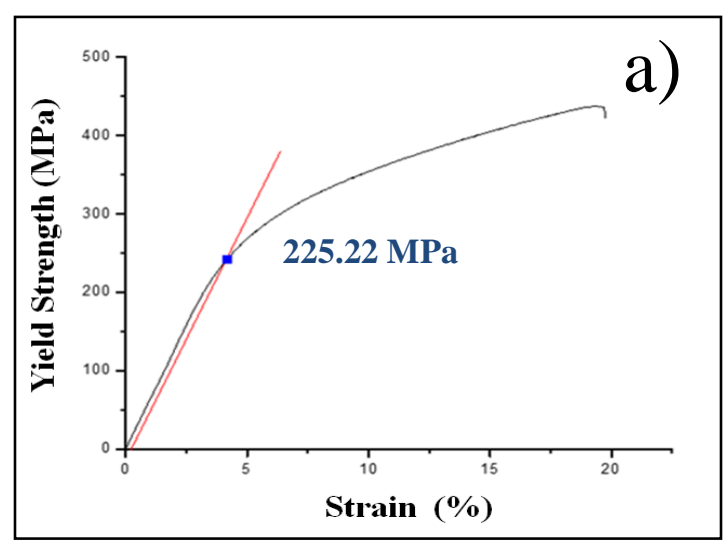

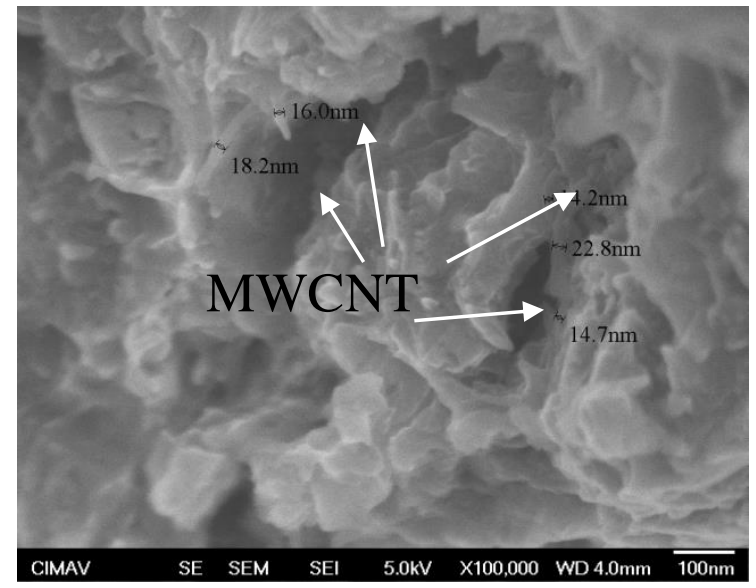

Figure 2. Surface morphology of $1 \mathrm{wt} \%$ MWNTC/A17075 composite after compression.

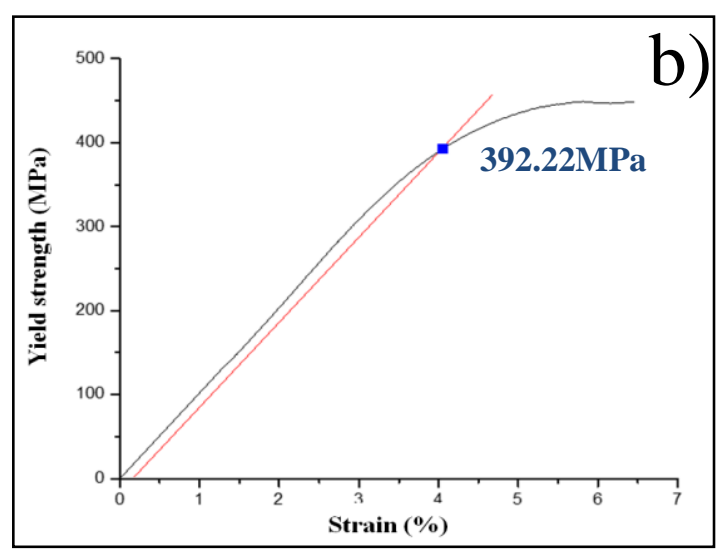

Figure 3. Compression properties of pure A17075 alloy and consolidated MMCs. The yield strength value of MMCs-1\% (a) is almost twice in comparison with pure alloy (b), the milling time was 2 hours. 